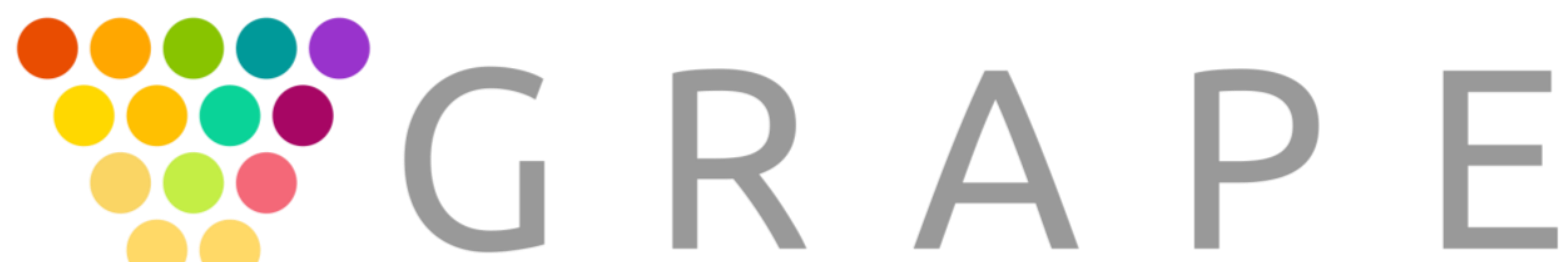

Group for Research in APplied Economics

Online and physical appropriation: evidence from a vignette experiment on copyright infringement

Michał Krawczyk, Joanna Tyrowicz, Wojciech Hardy

Foundation of Admirers and Mavens of Economics Group for Research in Applied Economics 


\section{Online and physical appropriation: evidence from a vignette experiment on copyright infringement}

\author{
Michał Krawczyk \\ University of Warsaw
}

\author{
Joanna Tyrowicz \\ FAME | GRAPE, IAAEU \\ University of Warsaw, IZA
}

\author{
Wojciech Hardy \\ University of Warsaw
}

\section{Abstract}

In this study we use a vignette experiment to inquire which features of online piracy make it ethically discernible from traditional theft. We find that the actual loss incurred by a victim, and especially a loss of a physical object have particularly strong bearing on ethical evaluation. Interestingly, in contrast to the claims that norms are inherently rotten in computer-mediated interaction, the patterns of ethical judgment in the online and offline contexts are very similar. These are mostly the characteristics of the deed themselves that explain differences in ethical judgment, and not a different perception of these characteristics in the online context. We interpret these findings in the context of legal regulations and the design of anti-piracy campaigns..

Keywords:

online piracy, ethical judgment, vignette experiment

\section{JEL Classification}

P31, D24, 047

\section{Corresponding author}

Wojciech Hardy, whardy@wne.uw.edu.pl

\section{Acknowledgements}

Authors would like to thank Piotr Cwiakowski and Marta Dyrkacz for excellent research assistance. At earlier stages of this work we received inspiring comments from Stuart P. Green, Anna KuklaGryz, Scott Vitell, two anonymous referees and participants of RES 2014, '5th Workshop on the Economics of ICTS' in Porto as well as seminars at London School of Economics, University of Warsaw and Warsaw School of Economics. The remaining errors are ours.

\section{Published by: $\quad$ FAME | GRAPE \\ ISSN: 2544-2473}

(c) with the authors, 2019 


\section{Introduction}

Since the advent of broadband Internet millions of users worldwide downloaded copyrighted content from unauthorized sources. Although studies such as LaRose et al. (2005) confirm that normative beliefs affect self-reported willingness to download content illicitly, there is also evidence that ethical concerns associated with such downloading are limited (Siegfried, 2004). Accordingly, economic models of piracy (Reavis Conner and Rumelt, 1991; Banerjee, 2003; Bae and Choi, 2006) usually abstract from ethical concerns about acquiring unauthorized content. ${ }^{1}$ In this paper we seek to understand the ethical doubts associated with "online piracy", with the premise that these ethical concerns may have a bearing on both theoretical modeling and policies. In the remainder of this paper, for brevity, we refer to "online piracy" or just "piracy" as act of downloading cultural content from unauthorized sources. ${ }^{2}$

The copyright holders portray piracy as an act of stealing. Recording Industry Association of America (RIAA) says that "piracy" is "too benign of a term". Also authorities, on occasion, use strong words when speaking of unauthorized downloading. For example, the vice-president of the USA, Joe Biden, stated "piracy is theft, clean and simple [...] It ain't no different than smashing a window at Tiffany's and grabbing [merchandise]". While the language of this discourse is a topic in itself (Denegri-Knott, 2004), it is also interesting why so many citizens reject labeling unauthorized downloading as theft.

One plausibly relevant difference between traditional theft and online piracy is that the former is by nature physical, whereas the later is computer-mediated. Already Benson (1985) shows that whitecollar crime offenders do not equate their deeds to other forms of theft, mostly emphasizing the distance associated with such form of crime. Indeed, Gottschalk and Smith (2011) provided insights into selfjustification techniques that can be applied to "online piracy", such as the denial of injury due to what they called an artificial dislocation of the crime (i.e. a form of "distancing oneself" from the consequences of the deed).

The debate on ethical aspects of "online piracy" parallels indeed the debates on the ethical aspects of many other phenomena that required a personal interaction in the past, but currently can be done without a direct contact, be it warfare drones modeled after video game consoles (Benjamin, 2013), reputation (Cheung et al., 2008; Ku, 2012) or even community building (Lin, 2007; Toral et al., 2009; BenbunanFich and Koufaris, 2013). Some prior research in these contexts suggests that online ethics may differ substantially from offline ethics (Lin, 2007; Holt and Copes, 2010; Agag et al., 2016).

Clearly, other factors should also be considered. For example, legal consequences of online piracy are different than for physical theft, which already reveals that from an ethical viewpoint (of most citizens and/or legislators) the two are not identical. Moreover, we should not confuse the two dimensions of differences: differences in ethical judgment due to the computer-mediation and differences in the underlying characteristics of the deed. Computer mediation may alter perceived ethical norms, because of potentially dehumanizing aspect of the environment, but it may still hold that copyright infringement is different from traditional theft not only due to deindividualtion Hinduja (2008). Indeed, there are substantive differences between traditional theft and "online piracy", beyond and above the deindividuating context of computer networks. Perhaps most importantly, theft deprives the victim of the object. By

\footnotetext{
${ }^{1}$ They only allow for some non-specific difference in "quality" between the original and the illicit copy, e.g. a fixed cost associated with reproduction or a degradation cost proportional to the individual customer's valuation of the product.

${ }^{2}$ Software downloading, uploading/sharing and plagiarism remain beyond the scope of interest of this paper, notably because software is protected sui generis and not as intellectual property per se.
} 
contrast, "online piracy" merely involves creating a copy of a digital file, so that an additional user can benefit from its existence, with no direct impact on anybody else (see also Introna, 2007). This distinction appears to be much more than merely hypocritical "denial of injury", because it is identified as one of key strategies to neutralize one's deviation from the social norm (Sykes and Matza, 1957).

In sum, our research question may be phrased broadly in the following manner: is there something about the Internet environment that makes stealing seem more acceptable? In more academic terms, we ask which difference between "piracy" and traditional theft makes the difference in ethical judgment? In order to address this question, we provide two vignette experiments in the spirit of Green (2012); Mudrack and Mason (2013); Aguinis and Bradley (2014). We construct a series of hypothetical stories in which we explicitly control for the characteristics of content acquisition that are likely to affect ethical judgment. We purposefully manipulate various characteristics of the deeds committed by a hypothetical Johnny, thus permitting the identification of the features of the copyright infringement in the traditional and online context and their role in driving the ethical judgment. ${ }^{3}$ Since every participant evaluates multiple stories, we are able to explore within and between subject variation in ethical judgment in order to single out the differences along the characteristics potentially relevant to the decision.

This study contributes to the literature in four ways. First, we provide the first attempt - to our best knowledge - to decompose the overall judgment of online and offline activities to the particular dimensions of the decision making process. We thus add to some earlier contributions, such as Shang et al. (2008), who focused on the distinction between the characteristics of the act itself and its consequences. Although vignette studies are frequently applied to analyze controversial behaviors, we are not aware of any study that would be able to compare explicitly traditional to computer-mediated behaviors in the same domain. Second, we structure our vignette experiment along the dimensions relevant in the policy debate as well as the process of decision making. Third, thanks to the design of the survey and subsequent econometric analysis, we are able to actually weigh the relevance of these dimensions for the ethical judgment in the case of online behaviors. Consequently, we are able to demonstrate that a relatively more permissive ethical judgment of online "piracy" is related to the objective characteristics of this act and not that much to a different ethical norm for online behaviors. Fourth, we analyze if the individual ethical norms concerning piracy diverge from the perceived prevailing social norms.

Our paper is structured as follows. In the next section we summarize the insights from earlier literature and the narratives of the policy debate. Section 3 discusses in detail the design of the two vignette experiments we employed. In section 4 we present the results. Limitations of our study are discussed in section 5, which also concludes with the policy recommendations and implications for the creative industries.

\section{Insights from earlier literature and policy debate}

Analyzing a decision maker in front of an ethically ambiguous situation, Hunt and Vitell (1986) proposed a conceptual dissection into deontological (a deed is good or evil in itself) and teleological (a deed is judged by its consequences) components of the ethical evaluation. Hunt and Vitell (1986) suggests that the weight given to either of these components may differ between people.

\footnotetext{
${ }^{3}$ Our approach is rooted in the theoretical delineation between deontological and teleological aspects of ethical judgment, as systematized by Hunt and Vitell (1986).
} 
The separation into the judgment of deed and its consequences may be particularly useful in the case of "online piracy". On the one hand, big part of the debate focuses on pushing forth a legal agenda, which by nature relates to the deed itself. On the other hand, argumentation raised on both sides relates to consequences of legal norm violations (e.g. "because of piracy publishers cannot sponsor new works or debutants" or "because of excessive prices, culture remains inaccessible to majority"). Also, empirical findings provide support to the relevance of the teleological dimension. Shang et al. (2008) demonstrate that when peer-to-peer network is payable, even strong orientation on property protection no longer drives deontological evaluation of file-sharing. ${ }^{4}$

There is a number of reasons why "online piracy" can be evaluated as different from a traditional theft. Green and Kugler (2010) design a vignette study to inquire the judgments on the acquisition of a test preparation tool. They find that the deed is generally considered more blameworthy when the tool was physical or if its taking excluded others from potentially using it. These observations provide a strong hint that "piracy" is seen in light very different from traditional theft. Similar insights follow from a review by Williams et al. (2010) on vignette studies (see also Lin et al., 1999; Higgins et al., 2005). Easley (2005) argue that downloaders perceive their behavior to be more similar to recording a song from the radio, rather than to shoplifting a $\mathrm{CD}$ from a store.

Against this background, Altschuller and Benbunan-Fich (2009); Robertson et al. (2012) focus on differences between "pirates" and other consumers. The former exhibit higher preference for risky behavior, less respect for rules, and less fear of being caught than the latter. Still, the act of online "piracy" is not necessarily related to the willingness to commit theft. Hill (2007) showed that downloading and shoplifting are unrelated, although in a related study Robertson et al. (2012) argues that downloaders are more likely to steal a $\mathrm{CD}$ from a store than non-donwloaders, provided that the risk of getting caught is sufficiently low (see also Wingrove et al., 2011).

One final factor that could explain the perceived distinction between "piracy" and shoplifting might be the non-physical nature of the former, much like in the literature on white collar crimes, see Benson (1985); Hasnas (2004); Gottschalk and Smith (2011). In fact, according to Gupta et al. (2004), an important reason why "pirates" seem to show little remorse may be that social norms that they seek to guide their choice are often obscure (see also Goles et al., 2008; Wang and McClung, 2012; Liang and Phau, 2012; Phau et al., 2013).

Summarizing, earlier literature has devoted considerable attention to two questions: first, are "pirates" inherently morally rotten and, second, when can their actions be justified given their consequences (or lack thereof). Useful and natural as they are, these approaches are implicitly based on an overly simplifying assumption that an act of piracy is homogeneous. Relative to the earlier literature, we seek to contribute to the literature by disentangling the impact each of these features has separately on the moral judgment of "online piracy".

In stark contrast to the findings of the empirical literature lies the policy debate. There are several prominent types of argumentation used to emphasize differences between the "online piracy" and theft -

\footnotetext{
${ }^{4}$ This approach is also related to the theoretical perspective offered by equity theory. Based on seminal contributions by Adams (1963) and Homans (1961), it proposes that individuals aim for a balance between their inputs (what they give) and outputs (what they receive) in any exchange. High price, inconvenient distribution channels might reduce consumers' perceived obligation towards the copyright holder, making digital piracy more ethically acceptable. By contrast, the consumer will tend to avoid causing losses on firms or individuals that she believes did not harm her. Equity theory also sheds light on the exchange of files in P2P networks - consumers may feel obliged to reciprocate benefits they obtained from others (Glass and Wood, 1996).
} 
as well as the lack thereof. Some of these arguments loosely allude to specific aspects of theft discussed in the theory of criminal law that might be absent in "piracy". However, there are also arguments unrelated to the legal context, but rather to the ethical aspects. In order to facilitate relating the features to the public debate, we provide below some quotes and citations for each of these features.

1. The most prominent argument concerns the loss, which is also a crucial delineation between intellectual and physical property (Landes and Posner, 1989). This argument is often referenced in the mass media: "A key element of stealing is that the one stolen from loses the object, which is not the case in file sharing since it is copied." (Larsson from TorrentFreak in: Ernesto, 2011). Indeed, if a hypothetical Johnny steals a DVD from a colleague, the colleague incurs a loss. By contrast, if Johnny copies files from a colleague, no loss is incurred by the colleague. In a broader definition of loss some want to include also earnings foregone by the publisher and/or retailer, relying on the assumption that Johnny would have purchased the DVD had he not copied it. This approach is conceptually controversial. Taking the words of a Minecraft developer Markus Persson as an example "There is no such thing as a 'lost sale' (...) Is a bad review a lost sale? What about a missed ship date?" (Masnick, 2011). In any case, there is no warranty that a hypothetical Johnny would indeed make a purchase from an authorized source in the absence of alternative means of obtaining given cultural content.

2. If a (potential or actual loss) occurs, its size, measured by the price of the product, is likely to be important: if it's expensive, it might be taken more seriously. "Borrowing" somebody's pencil is typically not considered such a big deal, even if there is no intention to actually return it. As digital distributions of many types of content tend to be cheaper (and Internet users have a general notion that they are or they should be, because "information wants to be free"), this dimension could also partly explain the lax ethical judgment of piracy compared to traditional stealing. Then again, a high price is one of pirates' favorite excuses not to purchase (e.g. point 7 in Hart, 2012). It seems therefore likely that the impact of price will be moderated by other factors, such as whether an actual loss occurs.

3. Closely related to the price dimension is whether an alternative is available at all. Lack of a legal alternative is also a very common justification of piracy (see e.g. points 3, 6, 8 by Hart, 2012). Consumers unable to purchase the authorized version may possibly be excused for obtaining a pirated copy instead (Introna, 2007). By contrast, pirating an easily and cheaply available product violates equity of the relationship between the copyright holder and the consumer. ${ }^{5}$

4. It is also relevant to acknowledge the owner of the good, differentiating between equals/peers and others (e.g. a colleague vs. the publisher, the state). For one, this dimension refers to the proportionality criterion in setting punishments - harm by individual to another individual is relatively larger than an identical harm by an individual to a state or a large firm (by the virtue of a marginal value). "When downloading a film (...) it is very easy to think that you're just stopping a few dollars from dropping into the pocket of a capitalist studio somewhere" says BetaNews journalist Mark Wilson (Wilson, 2013), see also points 9 and 10 reported by Hart (2012).

\footnotetext{
${ }^{5} \mathrm{Lau}$ (2007) showed that social acceptance of "pirated" software is negatively related to the availability of original versions. However, software is a special case, because it is subject to similar regulation as physical items, intellectual property is protected sui generis.
} 
5. Breach of protection measures is often emphasized. Digital pirates do not "smash a window at Tiffany's" as Joe Biden would have it. Although they may need to crack Digital Rights Management (DRM) protection, unauthorized access to virtual goods is generally much easier than to physical goods. "Piracy is not raiding and plundering Best Buys and FYEs, smashing the windows and running out with the loot. It's like being placed in a store full of every DVD in existence. There are no employees, no security guards," says Forbes' Paul Tassi (Tassi, 2012). Or, to make it a straw man, "It's okay to pirate copyrighted content because it's so easy to make copies" (James, 2013).

6. Another important aspect is the physicality of the deed. As a matter of fact, two aspects of this dimension should be distinguished: whether a physical action occurs and (requiring the former) whether a physical object is lost. Traditional theft will involve a physical loss whereas "piracy" does not have to involve even any physical action. The reason why this dimension was considered refers no longer to the way ethical norms are established but rather to the ethical doubts of modernity. It is often raised that communication technologies involve behaviors substantially different from traditional means of communication, e.g. hate speech in the Internet forums or the use of drones. Admittedly, it is easier to commit a crime with no conscience if one does not have to face the victim (Bernat and Makin, 2014). ${ }^{6}$

7. Piracy and theft may also differ substantially on the dimension of legality: in most countries of the world sharing is illegal, which might contribute to its negative reception on the ethical scale as well (expressive function of law Sunstein, 1996). By contrast, in line with the predictions of equity theory (Ajzen, 1991), in many social networks users who contribute to the community by uploading files enjoy respect and approval (as opposed to users who only benefit from downloading files, see e.g. Lin, 2007; Toral et al., 2009; Altschuller and Benbunan-Fich, 2009). In this particular case, legal norm and social norm are in stark contrast (at least between some groups of users).

8. Finally, and related to legality, a question arises if there is actual penalty for piracy. Even if illegal, it may effectively be tolerated; this is for example currently the case for downloading in the Netherlands. The lack of the sanctions weakens the norm, signaling that piracy is not a big deal.

The list above is meant as a somewhat comprehensive overview of the argumentation used in a policy debate concerning "online piracy". Some of the above dimensions (namely loss, peer, sharing) pertain to the consequences of the action, whereas others (namely online, physicality, and protection) focus solely on the nature of the deed itself, which corresponds to teleological and deontological characteristics respectively. Building on the insights from the literature and these classes of arguments we construct a vignette study in which responders provide ethical judgment of traditional and "online" violations of property rights over the same good. The arguments yield predictions to be tested via framing the characteristics of a deed to be evaluated by the respondents.

\footnotetext{
${ }^{6}$ The distinction between the online vs. offline environment is a closely related dimension here: most non-physical interchange nowadays is mediated by a computer network. Then again, non-physical yet offline transfer of content is an interesting case that might help establish which which dimension makes a difference; we will tackle it explicitly in Study 2.
} 
The above considerations leave aside claims such as "piracy is okay, because everybody does it". While it is virtually impossible to test empirically for the validity of such statements, we can test if social norm is indeed more lax than the individual one. One way to address this problem is to inquire about individual judgment and social norm separately.

The demarcation line between individual ethical judgment and perceived social norms is far from obvious (see Schoenberg and Ravdal, 2000, among others). The respondents in vignette experiments often refer to the latter when asked about the former. For example, individuals might find it hard to adequately process complete information about the circumstances under which the decision is made (cfr Schwartz and Tessler, 1972; Ajzen, 1991). Unauthorized sharing of content may be individually judged as ethically questionable despite the (injunctive) social norm being relatively lax - several studies such as Tang and Farn (2005) indicate that others' opinions have an independent effect on intention to engage in copyright infringement (see also Schultz, 2006, for a broader discussion of the importance of various social norms in enforcement of copyright). For this reason we will inquire the subjects to report social norms in addition to the individual judgments. To substantiate that actually social norm was elicited we use the incentive mechanism recently introduced by Krupka and Weber (2013).

\section{Methods}

We recognize that there could be two origins of difference between the traditional theft and "online piracy". First, there can be some objective differences in characteristics between "online piracy" and traditional theft. Second, the judgment of the characteristics of actions performed on the Internet may differ from the judgment of these very same attributes in the case of real life activities. This section describes the design of the survey, the acquisition of the respondents, the details of administering the survey, and the treatments implemented in our experimental vignette studies.

\subsection{Construction of the vignette surveys}

Vignette experiments are often used when eliciting justification for moral judgment, especially with reference to controversial choices. ${ }^{7}$ Typically, interviewees are asked to evaluate hypothetical yet realistic situations (Schoenberg and Ravdal, 2000). We pursue this method by constructing a series of stories where a colleague named Johnny admits to committing some deeds, which he originally thought of to be ethically acceptable, but is currently doubtful and asks the survey participants for an advice. His behavior was, in principle, controversial, but our description of each action was deprived of any judgmental statements. ${ }^{8}$ The only exception from this rule was the introduction to the survey, in which respondents were informed that Johnny has some doubts about what he has done and asks for the respondent's ethical judgment. The scale of judgment ranged from totally unacceptable (1) to fully acceptable (4). Each of Johnny's actions involved obtaining access to the same cultural good - a whole season of a TV series in Study 1 and a collection of music in Study 2.

The structure of the stories about deeds reflects realistic and policy relevant situations faced by most consumers interested in the consumption of cultural goods. The stories have been constructed by

\footnotetext{
${ }^{7}$ See e.g. Steinert and Lepping (2009) on violence in patient-doctor relationships, Abbey (2002) on alcohol-related sexual abuse, and Rettinger et al. (2004) on classroom cheating.

${ }^{8}$ See Appendix for the translation of the stories.
} 
Table 1: Stories used in Study 1

\begin{tabular}{|c|c|c|c|c|c|c|c|c|}
\hline No. & Story summaries & Loss & Alternative & Peer & Physical object & Protection & Sharing & Mean answer \\
\hline \multicolumn{9}{|c|}{ Screen A } \\
\hline 1 & Files copied, owner unaware & No & No & Yes & No & No & No & 2.75 \\
\hline 2 & Steal unused from colleague & No & No & Yes & Yes & No & No & 1.09 \\
\hline 3 & Colleague would lend, steal & Yes & Yes & Yes & Yes & No & No & 1.23 \\
\hline 4 & Steal one-time access code & Yes & No & Yes & No & Yes & No & 1.11 \\
\hline \multicolumn{9}{|c|}{ Screen B - DVD to share on-line } \\
\hline 5 & Buy & No & No & No & No & No & Yes & 2.47 \\
\hline 6 & Buy \& crack DRM & No & No & No & No & Yes & Yes & 2.31 \\
\hline 7 & Borrow & No & No & Yes & No & No & Yes & 2.17 \\
\hline 8 & Borrow \& crack DRM & No & No & Yes & No & Yes & Yes & 2.06 \\
\hline \multicolumn{9}{|c|}{ Screen $\mathrm{C}$ - download } \\
\hline 9 & Niche production & No & No & Yes & No & No & No & 2.61 \\
\hline 10 & Big label & No & No & No & No & No & No & 3.09 \\
\hline 11 & From $\mathrm{P} 2 \mathrm{P}^{* *}, \&$ w/o sharing & No & No & No & No & No & No & 2.56 \\
\hline 12 & From P2P** \& w/ sharing & No & No & No & No & No & Yes & 2.75 \\
\hline 13 & Despite available low cost & No & Yes & No & No & No & No & 2.82 \\
\hline \multicolumn{9}{|c|}{ Screen D - steal } \\
\hline 14 & From a store & Yes & No & No & Yes & No & No & 1.04 \\
\hline 15 & From a colleague & Yes & No & Yes & Yes & Yes & No & 1.02 \\
\hline \multicolumn{9}{|c|}{ Screen E - download instead of PWYW, niche } \\
\hline 16 & & No & Yes & Yes & No & No & No & 2.29 \\
\hline 17 & From P2P \& w/ sharing & No & Yes & Yes & No & No & Yes & 2.03 \\
\hline 18 & From P2P \& w/o sharing & No & Yes & Yes & No & No & No & 2.29 \\
\hline
\end{tabular}

Note: In Study 1 we did not include dimensions: price, penalty, and on-line. In each case 'Yes' means that this dimension is identified in Johnny's deed. Detailed stories in the Appendix. Order of the screens was randomized across respondents. Questions were randomized within each screen. * PWYW denotes pay-what-you-want. In each story the same cultural product is described. Respondents were informed about the meaning of PWYW. ** P2P denotes peer-to-peer networks (e.g. Torrents). Respondents were informed about the meaning of P2P.

switching particular dimensions 'on' and 'off', thus allowing to identify how these dimensions affect the judgment. For example, in one of the stories of Study 1 Johnny borrows a DVD from a colleague, cracks DRM protection and shares the files on the Internet, whereas in another story no DRM protection is mentioned, so the readers have no reasons to believe that Johnny actually had to crack any DRM. Table 1 and Table 2 summarize the structure of the Study 1 and Study 2, respectively. Detailed wording of each story is provided in the Appendix.

We have tried to make the stories only differ on the six dimensions considered in Study 1: loss, availability of alternatives, peer, physicality (loss of a physical object), protection breach, and sharing. Not only is the consumption good standardized across stories, but also - whenever possible - exact same wording is used. Universally across the survey, all emotionally loaded phrases were avoided (e.g. stealing, pirate, etc.) to let respondents feel free to express their own opinions. While, inevitably, any specific wording could have made a difference, all treatment groups received the same set of stories and questions, which implies that such potential influence is orthogonal to treatments (although it could still be relevant for our estimate of the impact of any specific dimension).

Given the number of dimensions, even after the reduction of irrelevant or infeasible combinations, we reached a total of 18 stories. Given numerous studies demonstrating that large number of questions 
Table 2: Stories used in Study 2

\begin{tabular}{|c|c|c|c|c|c|}
\hline \multirow[t]{2}{*}{ No. } & \multirow[t]{2}{*}{ Story summary } & \multirow[t]{2}{*}{ Loss } & \multirow[t]{2}{*}{ Price } & \multicolumn{2}{|c|}{ Mean answer } \\
\hline & & & & w/ penalty & w/o penalty \\
\hline \multicolumn{6}{|c|}{ Screen A: online stories } \\
\hline A1 & Password copied: extra access & No & Low & 1.66 & 1.65 \\
\hline $\mathrm{A} 2$ & Password copied: extra access & No & High & 1.60 & 1.67 \\
\hline A3 & Account hijacked & Yes & Low & 1.20 & 1.16 \\
\hline A4 & Account hijacked & Yes & High & 1.19 & 1.14 \\
\hline \multicolumn{6}{|c|}{ Screen B: offline, non-physical act } \\
\hline B1 & Files copied from a laptop & No & Low & 1.85 & 1.75 \\
\hline B2 & Files copied from a laptop & No & High & 1.72 & 1.77 \\
\hline B3 & Files cut\&pasted from a laptop & Yes & Low & 1.30 & 1.26 \\
\hline B4 & Files cut\&pasted from a laptop & Yes & High & 1.25 & 1.23 \\
\hline \multicolumn{6}{|c|}{ Screen C: offline, physical act } \\
\hline $\mathrm{C} 1$ & Files copied from a flash-drive & No & Low & 1.89 & 1.79 \\
\hline $\mathrm{C} 2$ & Files copied from a flash-drive & No & High & 1.79 & 1.77 \\
\hline $\mathrm{C} 3$ & Flash-drive replaced with an empty one & Yes & Low & 1.31 & 1.28 \\
\hline $\mathrm{C} 4$ & Flash-drive replaced with an empty one & Yes & High & 1.22 & 1.11 \\
\hline
\end{tabular}

Note: Detailed formulation of the stories in the Appendix. Some of the dimensions analyzed in Study 1 (i.e. Alternative, Peer, Protection, and Sharing) were on purpose not manipulated in Study 2. High price was set to 2000 PLN (one-time payment), whereas low value was 400 PLN. These values were designed to be substantially different and were informed by costs of subscriptions to platforms for music professionals.

per screen reduces the attention of the respondents and leads to a number of quality issues - e.g. satisficing or fatigue, see Stolte (1994) - the questions needed to be split between screens. We made sure that questions on the same screen were similar in terms of content. We emphasize graphically (e.g. with the use of bold font or underlining) the differences across the dimensions. For example, Screen A focused on the stories involving the TV series that Johnny got from a friend (fixing the source, thus also fixing the victim) and one by one we switched on the dimensions of loss, protection breach and physicality of the act. Clearly, not all combinations of these three dimensions are equally interesting and/or policy relevant. Consequently, we have narrowed the number of analyzed cases from eight to four, singling out each of the interesting dimensions. The values in the last column of Table 1 indicate that story 1 , involving no loss, no physical action and no breach of protection measures received much higher rating than the other three on screen A. Similarly, on Screen B, respondents were to compare in fact only two dimensions: peer and protection. All the four combinations were used. Ratings seem to be affected by both variables considered here. Screen C, in turn, puts together the combination of peer, availability of alternatives and sharing. The dimension of sharing could in principle work in either direction. On the one hand, Internet users tend to be grateful to those who upload and/or share files, because it is their effort that enables costless consumption. On the other hand, as we emphasized earlier, this is the delineation of legality, which previous studies found to be an important factor (see Robertson et al., 2012). Table shows that the conventional theft is universally condemned, no matter who the victim was. Finally, on screen E, sharing seemed to lower the rating slightly.

After completing the five screens with survey questions the respondents were also asked a (small) number of general questions. These additional variables include age, gender and educational attainment.

Inevitably, the stories of Study 1 differed in terms of several details. Hence, attributing the differences in ethical judgment to one of the six dimensions could only be done with caution. Moreover, the 
impact of some dimensions could only be identified based on the rating of two or three stories, making the results less clear in interpretation. In particular, separation of physicality and online dimensions was troublesome. To elaborate further on this angle, in Study 2 we focus on these two dimensions, adding the additional features of price and penalty, omitted in Study 1. By contrast, some dimensions that proved to be less relevant in Study 1 and/or difficult to be operationalized in our new set of stories were disregarded in Study 2.

Study 2 includes the following dimensions: online, penalty, price, physicality of the act, and loss. In study 2, the stories feature Johnny, an amateur DJ, using a colleague's music collection without permission or authorization. With this design, we were able to construct identical stories, except for the explicitly manipulated dimensions and the operationalization of the dimensions was always the same, see Appendix for detailed wording.

Similar to Study 1, the stories were divided into screens, with stories on the same screen sharing some dimensions (online and physical) and differing on the remaining dimensions (price and loss) for responders' convenience. This time the dimension of "physicality" was construed as involving a physical action rather than necessarily a loss of physical object; this was largely motivated by the fact that all our stories featuring the latter were given extremely low rating in Study 1. In other words, we already knew that responders would unanimously disapprove of behaviors that involve a loss of a physical item and we wanted to inquire the role of physical act. We sought to find out if already a physical action itself (without a loss of a physical object) triggers a similarly negative ethical judgment.

The interest of Study 2 was also in inspecting the role of penalty in ethical judgment. However, given the designed similarity of the stories, we feared that mentioning penalty even once to a responder would contaminate subsequent answers by anchoring their thoughts. To this end, we exploit the between-subject variation to measure the effect of penalty, with subject randomly assigned to one of the conditions: always mentioning penalty or never mentioning penalty.

\subsection{Respondents}

Ideally, such a survey should encompass a fairly representative sample from a population. However, the level and the modes of consumption of cultural goods are highly heterogeneous. Individuals less inclined to consume culture at all, are less likely to have expertise in understanding and judging the ethical context of "online piracy". Thus, even a representative sample would consist in large part of individuals inexperienced in consumption - from both authorized and unauthorized sources - of the cultural goods. Given the complexity of intellectual property rights regulations, many Internet users may be unaware which forms of acquiring content are legal (and yet potentially ethically questionable) and which are not. Since the view of legality largely affects ethical judgment - (e.g. Gupta et al., 2004) - intensive culture consumers should be also relatively more proficient in understanding the copyright.

In Study 1 we sought to obtain answers from respondents who are particularly aware of the legal rules and potentially also a broader, ethical context concerning the online distribution of cultural goods. ${ }^{9}$ To this end we issued survey invitations via Facebook fan pages endorsing authorized distribution of cultural content in Poland. The fan page owners were both NGOs and business organizations ${ }^{10}$ who had

\footnotetext{
${ }^{9}$ This survey was preceded by a personally assisted interview and an online pre-test study on a pool of students invited from an experimental subject pool at the Faculty of Economic Sciences, University of Warsaw. We focused on inquiring the clarity of the questions as well as feasible duration of the survey. Detailed log from both tests available upon request.

${ }^{10}$ We benefited from partnership with Legalna Kultura [Legal Culture], Fundacja Nowoczesna Polska [Modern Poland
} 
on overall reach of app. 30000 fans altogether.

The invitation to participate in the survey was placed officially on the wall by the entities which operate each of the fan pages. The invitation comprised information that the University of Warsaw is currently organizing a study to understand better the ethical valuation of online behaviors. We did not declare the specific objective, nor the method of the study. All respondents were informed that the survey is anonymous and no inference will be made based on individual data. The invitation was displayed twice by each of the four partners in this study, each time giving the interested Internet users up to two weeks to fill in the survey. Given that the invitation was displayed on Facebook pages, we cannot report a reliable response rate (the information on how many people actually displayed the invitation is only available to a Facebook page administrator).

Our final sample in Study 1 contains ratings of up to 18 stories by 129 respondents. We reach a sample of 2009 person - story observations. While our sample is fairly young (median age is 27 years old), so are the Internet users in general. According to CBOS (2013) report, Polish people below 35 spent, in 2013, almost twice as many hours surfing the Internet as the rest of the population - they were also mainly people with at least secondary education; also see Cole (2013). Also younger population is more likely to acquire content online, both from authorized and unauthorized sources, see Bai and Waldfogel (2012) for authorized acquisition and Svensson et al. (2014) for the users of The Pirate's Bay.

Admittedly, we have been somewhat disappointed with the number of responders, especially given the cumbersome recruitment procedure. We also wanted to check in a larger group than just a small pilot session if reaching out to a different subject pool would alter the findings. Thus, we run our Study 2 in our standard subject pool that consists mostly of students and recent graduates. We were able to recruit 384 individuals out of 1200 invited to take part in the survey. Not surprisingly, the responders of Study 2 were younger, with the median of 23 years.

\subsection{Treatments}

Many earlier studies found that individuals often consider actions socially (more) acceptable, while they are convinced they would never undertake them themselves. This is especially true in the case of controversial issues (Elster, 1989; Ostrom, 2000). In the case of "online piracy" it has been demonstrated a number of times that individual judgment reflects the beliefs of the (individually) important trendsetters (Al-Rafee and Cronan, 2006). Should this be true in general, one could expect that individual norm would become gradually more permissive, ceteris paribus, reinforcing the acquiescence.

To address the points raised by the literature, in Study 1 we designed three alternative elicitation mechanisms, treatments. The first one provides individual judgment (IJ) of the presented stories. The second group was asked about their perception of the social norm (SN) concerning the presented situations. Respondents assigned to either of the two treatment groups were informed that six of them would be selected at random to receive 100 PLN (ca 30 USD) each.

The remaining one-third of the respondents faced the same task as SN, except that they were incentivized to give truthful answers, using the mechanism of Krupka and Weber (2013). We denote this treatment as incentivized social norm (ISN). Before the respondents were shown any of the stories, they were informed that after the experiment we would pick one story at random. Respondents who give the modal judgment pertaining to this story would be eligible to participate in the drawing of the prizes. Re-

Foundation], Centrum Cyfrowe: Projekt Polska [Digital Center: The Poland Project], and IAB Polska [IAB Poland] 
sponders had the incentive to indicate what they considered the prevailing social norm. The introduction to the survey gave examples illustrating how exactly the award scheme works. We have allocated the remaining prizes in a way assuring that the expected prize in each treatment was identical.

The SN-ISN comparison should give us some sense of data quality - large differences would indicate that without incentives respondents are unwilling to disclose their opinions. Else, we may more confident that responses given in IJ are also truthful. The comparison between IJ and the other two treatments will help us discover differences between social and individual norms as mentioned before.

Since invitations were distributed online, we could not control who "clicks" on which treatment survey. In addition, Facebook facilitates sharing of posts, which could further blur the treatment assignment. To address this difficulty, randomization across treatments occurred after individuals clicked on the invitation link to participate in our survey. Consequently, treatments were randomized across all the participants after they decided to participate in the survey.

In Study 2, we also included IJ and SN, giving away six prizes of 100 PLN each, at random. Since Study 1 did not confirm differences between incentivized and standard measurement of the social norm, in Study 2 we drop the ISN design and only elicit IJ and SN evaluations.

\section{Results}

The key question in our project is whether or not the determinants of ethical judgment will differ between the stories describing the "real" world and the stories concerning computer-mediated situations. For the sake of brevity and because it fits well the context of digital "piracy" we refer to the latter as Internet stories and to the former as traditional stories. Given the characteristics of our metric (a rating on a scale from 1 to 4, from totally unacceptable to fully acceptable), we employ an ordered logit, the reported coefficients are equivalent to marginal effects. For the sake of robustness, we cluster standard errors at subject level.

\subsection{Study 1}

The baseline of pooled results is described in column (1) of Table 3. These pooled results lend support to the intuitive predictions: the characteristics of the deeds enter the model with the expected negative signs and are significant. The only exception is the availability of alternatives: although it is negative in most specifications, it is typically insignificant. It is troubling to understand why the availability of alternatives has proven quantitatively the least important, but potentially a low price of the authorized version may signal in fact low quality. Furthermore, not paying a small price involves little harm in terms of potentially lost revenue.

We also find that there is little statistical difference in evaluating the computer-mediated appropriation when compared to traditional one. In particular, the role of loss is as pronounced in both contexts. Similarly, if infringement has the features of a physical loss, it has very strong negative bearing on the ethical judgment. Note that both these characteristics are typically absent in the context of "online piracy". We have formally tested for equality of coefficients estimated in columns (3) and (4) finding economically irrelevant, yet statistically significant difference for "loss" dimension - inflicting a loss on someone over the Internet implies actually more negative judgment, possibly because direct harm over Internet is redundant. For a clearer view on the differences between online and traditional settings, we 
also extend the comparison in Study 2 (see section 4.2).

In line with the public debate, the peer dimension is negative (lower statistical significance in the traditional stories owes to the smaller sample size). In the case of protection breach and sharing, we argued the effects may go both way: the community of culture consumers in the unauthorized sources greatly appreciate sharing and removing the electronic protection measures. However, both involve premeditation and purposeful activity, not merely ad hoc consumption of culture. The ultimate outcome appears to be negative across our specifications, with effects for ethical judgment of a similar magnitude. Note however, that these three dimensions are substantially less relevant for the ethical judgment than loss and physicality dimension.

Much against the public debate, the existence of an alternative stands out with differing signs for the online and traditional context. Whereas it becomes statistically significant and more negative for the online stories, it is highly positive and significant for the traditional ones. Importantly, this last result is driven by only one story (out of five traditional) with an existing alternative mentioned, and the alternative wording specifically admits that the 'victim' would be partially 'ok' with Johnny taking the item (even if the 'victim' would rather that Johnny returned it later; see story 3 in Appendix A).

The general results hold across various robustness checks. For example, we control for the responders' personal characteristics (age, gender and labor force status) in column (2) and the results are the same as in a larger sample without those controls. ${ }^{11}$ Also when we exclude the most obvious cases of property violation (columns (5), (7) and (8)), the ranking and the relative strength remain essentially the same, as is the case when we exclude the responders who finished any of the screens unusually fast (columns (6), (7) and (8)).

Individual judgment proves to be more restrictive than the social norm, as is inferred from the treatment dummies in Table 3. This effect becomes insignificant in smaller samples, but the sign of the individual judgment dummy versus the social norm is always negative. This is in line with previously reported results, e.g. Bateman et al. (2013); Moores and Chang (2006). While the social norm seems to be more lax, there is no effect of incentivizing truthful and careful responses, as suggested by Krupka and Weber (2013). This suggests that already in the SN our responders were typically determined to answer in a thoughtful and honest way. In particular, even individuals with strong views did not seem reluctant to disclose them under SN.

\subsection{Study 2}

The aim of Study 2 is to elaborate the role of loss and physicality in the ethical judgment, especially exploiting the potential heterogeneity between the online and traditional context. In particular, we enrich the dimension through systematically manipulating the size of the price and penalty risk. The price plays primarily the role of addressing the public debate issue, but since the context for Study 2 is universally a peer, it also allows us to isolate the size of the loss from simply the mere fact of a loss. The penalty hints the responders with the "local" regulative norm. Given this special context of stories in Study 2, it is not surprising that the mean ethical judgment proves to be somewhat lower, recall the last two columns of

\footnotetext{
${ }^{11}$ The reduction from 129 to 127 responders in subsequent regressions comes from two unfinished questionnaires that contained ratings only for some of the 'traditional' stories. Since we randomized the order of the screens with questions, such occurrences do not affect our results. The reduction from 129 to 96 responders follows from the fact that the questions about individual characteristics were not required in Study 1. This reduced sample size does not change the general estimates and in Study 2 we make individual roster as compulsory as the vignette questions.
} 
Table 3: Study 1: Determinants of evaluations

\begin{tabular}{|c|c|c|c|c|c|c|c|c|}
\hline \multirow[b]{2}{*}{ Dimension of act } & \multirow{2}{*}{\multicolumn{2}{|c|}{ All }} & \multicolumn{2}{|c|}{ Only } & \multicolumn{3}{|c|}{ online and traditional stories } & \multirow{2}{*}{$\begin{array}{c}\text { Only } \\
\text { online } \\
(8)\end{array}$} \\
\hline & & & $\begin{array}{c}\text { online } \\
\text { (3) }\end{array}$ & $\begin{array}{l}\text { traditional } \\
\text { (4) }\end{array}$ & $\begin{array}{c}\text { w/o } 14 \& 15 \\
\text { (5) }\end{array}$ & $\begin{array}{c}\text { w/o fast } \\
\text { (6) }\end{array}$ & $\begin{array}{c}(5) \&(6) \\
\text { (7) }\end{array}$ & \\
\hline Loss & $\begin{array}{c}-2.177 * * \\
(0.236)\end{array}$ & $\begin{array}{c}-2.383^{* *} \\
(0.291)\end{array}$ & $\begin{array}{c}-3.747 * * \\
(0.452)\end{array}$ & $\begin{array}{l}-1.342 \\
(0.726)\end{array}$ & $\begin{array}{c}-2.126^{* *} \\
(0.328)\end{array}$ & $\begin{array}{c}-1.737 * * \\
(0.325)\end{array}$ & $\begin{array}{c}-1.747 * * \\
(0.489)\end{array}$ & $\begin{array}{c}-2.966^{* * *} \\
(0.579)\end{array}$ \\
\hline Alternative & $\begin{array}{l}-0.197 \\
(0.115)\end{array}$ & $\begin{array}{c}-0.188 \\
(0.135)\end{array}$ & $\begin{array}{c}-0.364 * * \\
(0.112)\end{array}$ & $\begin{array}{c}2.339 * * \\
(0.729)\end{array}$ & $\begin{array}{l}-0.196 \\
(0.116)\end{array}$ & $\begin{array}{c}-0.174 \\
(0.182)\end{array}$ & $\begin{array}{l}-0.170 \\
(0.184)\end{array}$ & $\begin{array}{l}-0.312 \\
(0.187)\end{array}$ \\
\hline Peer & $\begin{array}{c}-0.678 * * \\
(0.088)\end{array}$ & $\begin{array}{c}-0.765^{* *} \\
(0.107)\end{array}$ & $\begin{array}{c}-0.651 * * \\
(0.096)\end{array}$ & $\begin{array}{l}-0.942 \\
(0.559)\end{array}$ & $\begin{array}{c}-0.687 * * \\
(0.092)\end{array}$ & $\begin{array}{c}-0.708^{* *} \\
(0.133)\end{array}$ & $\begin{array}{c}-0.702 * * \\
(0.135)\end{array}$ & $\begin{array}{c}-0.683 * * \\
(0.154)\end{array}$ \\
\hline Physical & $\begin{array}{c}-2.786^{* *} \\
(0.229)\end{array}$ & $\begin{array}{c}-2.951 * * \\
(0.281)\end{array}$ & & $\begin{array}{c}-4.572 * * \\
(0.468)\end{array}$ & $\begin{array}{c}-2.749 * * \\
(0.280)\end{array}$ & $\begin{array}{c}-2.779 * * \\
(0.289)\end{array}$ & $\begin{array}{c}-2.787 * * \\
(0.397)\end{array}$ & \\
\hline Protection & $\begin{array}{c}-0.576^{* *} \\
(0.089)\end{array}$ & $\begin{array}{c}-0.592 * * \\
(0.094)\end{array}$ & $\begin{array}{c}-0.334 * * \\
(0.092)\end{array}$ & & $\begin{array}{c}-0.591 * * \\
(0.098)\end{array}$ & $\begin{array}{c}-0.768 * * \\
(0.151)\end{array}$ & $\begin{array}{c}-0.764 * * \\
(0.164)\end{array}$ & $\begin{array}{c}-0.524 * * \\
(0.159)\end{array}$ \\
\hline Sharing & $\begin{array}{c}-0.535^{* *} \\
(0.104)\end{array}$ & $\begin{array}{c}-0.615^{* *} \\
(0.115) \\
\end{array}$ & $\begin{array}{c}-0.671 * * \\
(0.112)\end{array}$ & & $\begin{array}{c}-0.528 * * \\
(0.104)\end{array}$ & $\begin{array}{c}-0.544 * * \\
(0.156)\end{array}$ & $\begin{array}{c}-0.542 * * \\
(0.150)\end{array}$ & $\begin{array}{c}-0.660 * * \\
(0.159)\end{array}$ \\
\hline Treatments & \multicolumn{8}{|c|}{ Social norms (as base) } \\
\hline Individual judgment & $\begin{array}{c}-0.805^{* *} \\
(0.279)\end{array}$ & $\begin{array}{c}-0.693 * \\
(0.321)\end{array}$ & $\begin{array}{c}-0.815^{* *} \\
(0.300)\end{array}$ & $\begin{array}{c}-0.895 * \\
(0.421)\end{array}$ & $\begin{array}{c}-0.816^{* *} \\
(0.279)\end{array}$ & $\begin{array}{l}-0.581 \\
(0.410)\end{array}$ & $\begin{array}{l}-0.567 \\
(0.409)\end{array}$ & $\begin{array}{l}-0.551 \\
(0.439)\end{array}$ \\
\hline Incentivized social norm & $\begin{array}{l}-0.463 \\
(0.249)\end{array}$ & $\begin{array}{l}-0.276 \\
(0.276) \\
\end{array}$ & $\begin{array}{l}-0.489 \\
(0.281)\end{array}$ & $\begin{array}{l}-0.389 \\
(0.341) \\
\end{array}$ & $\begin{array}{l}-0.460 \\
(0.252)\end{array}$ & $\begin{array}{l}-0.594 \\
(0.372) \\
\end{array}$ & $\begin{array}{l}-0.579 \\
(0.376) \\
\end{array}$ & $\begin{array}{l}-0.734 \\
(0.409) \\
\end{array}$ \\
\hline No. of observations & 2009 & 1709 & 1446 & 563 & 1769 & 937 & 821 & 669 \\
\hline No. of individuals & 129 & 96 & 127 & 127 & 127 & 65 & 63 & 63 \\
\hline Individual characteristics & No & Yes & No & No & No & No & No & No \\
\hline
\end{tabular}

Note: ordered logit, acceptability rating as dependent variable in all models (1-totally unacceptable, 4-fully acceptable). Individual controls in column (2) include age, gender and labor market status. In columns (3) and (4) we keep all the individuals, but drop stories which are not related to traditional and Internet context, respectively. In column (5) we keep all the individuals, but drop stories 14 and 15. In column (6) only answers of responders who took more than the 1st quartile of response times on all the screens. In column (7) we combine exclusions specified in (5) and (6) jointly. Column (8) reports results for exclusions specified in (4), (5) and (6) jointly. All regressions include control variables for survey duration and the screen number (detailed estimates available upon request). The 'Internet' stories are ones where at least part of the evaluated action occurred online (i.e. stories 4 to 13 and 16 to 18; see the Appendix for full story descriptions). Asterisk denote statistical significance, with $* p<0.05 ; * p<0.01$. Standard errors are reported in parentheses.

\section{Table 2.}

Despite the difference in design (an in average ethical judgment), Study 2 strongly corroborates the findings of Study 1, see Table 4. Specifically, actions involving a loss are evaluated more harshly and individual judgments are stricter than the perception of social norms. These findings are robust across all specifications, while specification with interactions (4) suggests that the impact of loss is also mediated by physicality of the act. Unlike in Study 1, physicality per se is not relevant for the ethical judgment, but in the setting of Study 2, physicality referred to a physical act, whereas the stories in the first study it referred to a physical object. The difference between act and object appears to be relevant for ethical judgment although one has to be cautious about jointly interpreting the results from two separate experiments.

The responders were more negative about infringements of more valuable cultural content (higher price), but curiously this is not due to the fact that potential loss is higher: the interaction term between loss and high price is not significant and it is of relatively small magnitude. This result is robust across specifications. Note that with the interactions in column (4), the interpretation of loss and high price 
dimension is different than in the rest of the specifications (loss of low price and high price for no loss scenarios).

The debate on the role of penalty often emphasizes that the very risk of penalty itself is a signal about the prevailing social norm, thus informing the individual judgment as well. Our study suggests that this type of reasoning may be misguided in a sense that naturally there appears to be some signal in information about penalty (the estimated coefficients are negative), but this signal is very noisy (coefficients are estimated imprecisely). Possibly, our risk of penalty could have been too weak of a signal to deliver significant results(the stories emphasize the direct penalty by the boss of Johnny, not the legal norm). Yet, even if it were to be stronger, our study suggests that the dimension of loss is substantially more relevant for forming the ethical judgment. In other words: if people are not convinced that a given action results in a loss, whether or not a penalty may be involved is of marginal importance to their ethical evaluation.

Table 4: Study 2: Determinants of evaluations

\begin{tabular}{|c|c|c|c|c|c|c|c|}
\hline & \multicolumn{4}{|c|}{ All stories } & \multirow{2}{*}{$\begin{array}{c}\text { Physical } \\
\text { (5) }\end{array}$} & \multirow{2}{*}{$\begin{array}{c}\text { Online } \\
\text { (6) }\end{array}$} & \multirow{2}{*}{$\begin{array}{c}\text { Offline } \\
\text { non-physical } \\
\text { (7) }\end{array}$} \\
\hline & (1) & (2) & (3) & (4) & & & \\
\hline Loss & $\begin{array}{c}-1.864 * * \\
(0.116)\end{array}$ & $\begin{array}{c}-1.880 * * \\
(0.117)\end{array}$ & $\begin{array}{c}-1.907 * * \\
(0.119)\end{array}$ & $\begin{array}{c}-1.763 * * \\
(0.126)\end{array}$ & $\begin{array}{c}-2.184 * * \\
(0.147)\end{array}$ & $\begin{array}{c}-1.862 * * \\
(0.146)\end{array}$ & $\begin{array}{c}-1.704 * * \\
(0.129)\end{array}$ \\
\hline High Price & $\begin{array}{c}-0.140 * * \\
(0.040)\end{array}$ & $\begin{array}{c}-0.142 * * \\
(0.040)\end{array}$ & $\begin{array}{c}-0.143^{* *} \\
(0.040)\end{array}$ & $\begin{array}{c}-0.129 * * \\
(0.041)\end{array}$ & $\begin{array}{c}-0.206^{* *} \\
(0.053)\end{array}$ & $\begin{array}{l}-0.062 \\
(0.056)\end{array}$ & $\begin{array}{c}-0.156^{* *} \\
(0.050)\end{array}$ \\
\hline High Price $*$ Loss & & & & $\begin{array}{l}-0.047 \\
(0.079)\end{array}$ & & & \\
\hline Physical Act & $\begin{array}{l}-0.035 \\
(0.060)\end{array}$ & $\begin{array}{l}-0.035 \\
(0.061)\end{array}$ & $\begin{array}{l}-0.031 \\
(0.061)\end{array}$ & $\begin{array}{c}0.081 \\
(0.061)\end{array}$ & & & \\
\hline Physical Act * Loss & & & & $\begin{array}{c}-0.361 * * \\
(0.100)\end{array}$ & & & \\
\hline Online & $\begin{array}{c}-0.365 * * \\
(0.082)\end{array}$ & $\begin{array}{c}-0.370 * * \\
(0.082)\end{array}$ & $\begin{array}{c}-0.370 * * \\
(0.083)\end{array}$ & $\begin{array}{c}-0.365 * * \\
(0.082)\end{array}$ & & & \\
\hline Treatments & \multicolumn{7}{|c|}{ Social norms and no penalty as base } \\
\hline Individual judgment & & $\begin{array}{c}-0.437 * * \\
(0.158)\end{array}$ & $\begin{array}{c}-0.492 * * \\
(0.158)\end{array}$ & $\begin{array}{c}-0.493 * * \\
(0.158)\end{array}$ & $\begin{array}{c}-0.619 * * \\
(0.174)\end{array}$ & $\begin{array}{l}-0.485^{*} \\
(0.191)\end{array}$ & $\begin{array}{l}-0.388 * \\
(0.173)\end{array}$ \\
\hline Risk of Penalty & & $\begin{array}{l}-0.169 \\
(0.157)\end{array}$ & $\begin{array}{l}-0.175 \\
(0.156)\end{array}$ & $\begin{array}{l}-0.174 \\
(0.156)\end{array}$ & $\begin{array}{c}-0.348^{*} \\
(0.171)\end{array}$ & $\begin{array}{l}-0.063 \\
(0.186)\end{array}$ & $\begin{array}{l}-0.116 \\
(0.174)\end{array}$ \\
\hline No. of observations & 4,608 & 4,608 & 4,608 & 4,608 & 1,536 & 1,536 & 1,536 \\
\hline No. of individuals & 384 & 384 & 384 & 384 & 384 & 384 & 384 \\
\hline Individual characteristics & No & No & Yes & Yes & Yes & Yes & Yes \\
\hline
\end{tabular}

Note: ordered logit, acceptability rating as dependent variable in all models (1-totally unacceptable, 4-fully acceptable). In column (1) estimates exploit only within-subject variation. The treatment effects from column (2) onwards are identified with between-subject variation. Columns (5) to (7) use the specification from (3) but separately for each screen. See the Appendix for full story descriptions. Asterisk in the table denote statistical significance of the estimates with * $p<0.05$; ** $p<0.01$. Standard errors reported in parentheses.

Finally, the online transgressions appear to be viewed as more negative than traditional transgressions. At the same time, the drivers of the ethical decision are highly robust for both offline and online contexts. Namely, the coefficient on online dimension is systematically negative, significant and large by comparison to price or physicality dimension. However, the comparison between online and offline contexts reported in columns (5)-(7) reveals that the role of loss, price, penalty and social vs. individ- 
ual norm are statistically equivalent across subsamples of stories. We interpret this finding to suggest that despite efforts to make the stories very comparable across online and offline contexts, responders may still sense differences between the two contexts. Notably, the results in Study 1 and Study 2 are consistent in this respect: ethical judgment is actually harsher in the online context.

\section{Discussion and conclusions}

Despite copyright owners' narrative of "online piracy" being equivalent to physical theft, millions commit it daily around the world with plausibly little remorse. Are computers making us less ethical? Or do we copy content from unauthorized distributors because there are substantive ethical differences between "online piracy" and theft? Or perhaps digital communication simply make transgressions themselves more ethically acceptable? Our objective in this study was to identify the effects of ethical judgment from the effects of inherent characteristics of online and offline morally questionable deed. We offer a novel way to study these effects, contributing to the debate on the ethics and computer-mediation. Our study reports results from two experiments on a limited number of non-representative responders. This methodology is conventional in experimental economics, but it is obviously a source of concern for interpretations outside the sample and external validity. The subject pools in the two studies of our paper differ: Study 1 was implemented among subject interested in authorized distribution of cultural content online, whereas Study 2 was implemented on a regular student pool of experiment participants. The results are similar in some key aspects, but our subjects were not sampled from a general population. With this limitation in mind, we henceforth provide discussion of our results as if they were informative of populations in general.

Our main result suggests that there are no important differences in how deeds are evaluated between virtual and real world. The characteristics of a deed that are relevant to determining ethical judgment of appropriation - play similar role in computer-mediated and traditional context. If anything, inflicting a loss in computer-mediated context is judged in a harsher way than in traditional context. Thus, there is nothing about computer-mediation in determining the ethical judgment of "online piracy" - it is just the context that differs. Notably, "online piracy" typically involves no direct loss and even so, it is not a loss of a physical object. These inherent characteristics of computer-mediated copyright infringement explain why the social and individual norms concerning "online piracy" are more lax than the social and individual norms concerning a traditional theft. We show that no single dimension accounts for the difference between the ethical evaluation of "online piracy" and traditional theft. In particular, teleological factors, such as whether the act leads to a direct loss, play a major role.

While designing the vignette experiment we have been careful to address many potential caveats. However, there remain a few questions that cannot be answered based on our study. The tackling of the loss dimension is generally weaker than it is for the other five. First, it does not explicitly address the fructus. In fact, we give little room to the argument of foregone earnings (and the awareness of these non-materialized losses), as this topic is so vast and diversified in terms of context that it deserves a dedicated study.

Also, the approach taken with regard to the availability of alternatives does not entirely address the issues appearing in the public debate. Namely, the debate focuses on acquiring content, when the original distributor chooses not to provide a particular good in a particular form (e.g. digital format) or to a particular group of consumers (e.g. service unavailable in some countries). In our vignette experiment 
availability of an alternative proved irrelevant for the ethical judgment, except when in the context of Internet. In fact, many stakeholders argue in favor of unauthorized distribution exactly because of content being impossible to find, but when it is available - mostly the pricing strategies are being debated, not the 'right to violate' in general.

An important limitation of any vignette experiment is that observing declarations is not the same as observing actions. Indeed, it is relatively difficult to judge to what extent our conclusions would be affected by a reality check. Finally, while we may say something about social norms and ethical judgments concerning piracy, we cannot offer much in terms of a deeper understanding of their origins and historical development. Achieving this goal would require rerunning the study periodically as a quasi-panel or employing an altogether different approach using secondary data.

Besides contributing to the literature of the field, this paper also offers some interesting policy insights. First, since individual ethical judgment is more strict than the social norm, campaigns emphasizing this discrepancy are likely to be effective in making the social norm more strict, which could translate into reducing the prevalence of downloading from unauthorized sources.

Second, we demonstrate that characteristics of "online piracy" (i.e. the fact that it usually involves no direct loss) have a bearing on ethical judgment of this phenomenon. Namely, we find in Study 1 that if loss indeed occurs in the context of online appropriation, ethical judgment is harsher; in Study 2 the dummy for Online per se already makes a negative impact. In this sense, our results go against treating Internet relaxing ethical norms per se, as has been argued in earlier literature, e.g. review by Denegri-Knott (2004) and numerous citations therein.

It is our interpretation of the results that it may be unfortunate to both sides of the conflict to emphasize the Internet context of "online piracy". For RIAA and promoters of authorized distribution of content it may be impossible to effectively set at par theft and downloading unless they actually demonstrate the scope for loss (the scope for demonstrating physicality is rather limited). For the promoters of unconstrained content sharing, disembarrassing the (possibly majority of) the Internet users of the thief's stigma is not likely to effectively happen via framing the Internet as "the home of free". In fact, Internet users already do acknowledge the ethical differences between theft / downloading on the one hand and purchasing / taking for free on the other hand. However, as in their opinion downloading entails no loss, it is easily justified as a viable alternative to purchasing.

From the viewpoint of law-making, our findings suggest that strengthening legal enforcement of copyright loss will likely result in deepening the discrepancy with the public's perception of what is right. As long as "online piracy" remains a non-physical activity with no specific barriers to be overcome, causing only indirect losses to distant entities, the general audience will strongly object to any severe laws against it and, should they nevertheless be passed, circumvent them en masse. 


\section{References}

Abbey, A., 2002. Alcohol-related sexual assault: A common problem among college students. Journal of Studies on Alcohol and Drugs (14), 118.

Adams, J. S., 1963. Towards an understanding of inequity. The Journal of Abnormal and Social Psychology 67 (5), 422.

Agag, G., Agag, G., El-masry, A., El-masry, A., Alharbi, N. S., Alharbi, N. S., Ahmed Almamy, A., Ahmed Almamy, A., 2016. Development and validation of an instrument to measure online retailing ethics: consumers perspective. Internet Research 26 (5), 1158-1180.

Aguinis, H., Bradley, K. J., 2014. Best practice recommendations for designing and implementing experimental vignette methodology studies. Organizational Research Methods 17 (4), 351-371.

Ajzen, I., 1991. The theory of planned behavior. Organizational behavior and human decision processes 50 (2), 179-211.

Al-Rafee, S., Cronan, T. P., 2006. Digital piracy: Factors that influence attitude toward behavior. Journal of Business Ethics 63 (3), 237-259.

Altschuller, S., Benbunan-Fich, R., 2009. Is music downloading the new prohibition? What students reveal through an ethical dilemma. Ethics and Information Technology 11 (1), 49-56.

Bae, S. H., Choi, J. P., 2006. A model of piracy. Information Economics and Policy 18 (3), 303-320.

Bai, J., Waldfogel, J., 2012. Movie piracy and sales displacement in two samples of chinese consumers. Information Economics and Policy 24 (34).

Banerjee, D. S., 2003. Software piracy: a strategic analysis and policy instruments. International Journal of Industrial Organization 21 (1), 97-127.

Bateman, C. R., Valentine, S., Rittenburg, T., 2013. Ethical decision making in a peer-to-peer file sharing situation: The role of moral absolutes and social consensus. Journal of Business Ethics 115 (2), 229240.

Benbunan-Fich, R., Koufaris, M., 2013. Public contributions to private+collective systems: the case of social bookmarking. Internet Research 23 (2), 183-203.

Benjamin, M., 2013. Drone warfare: Killing by remote control. Verso Books.

Benson, M. L., 1985. Denying the guilty mind: Accounting for involvement in a white-collar crime. Criminology 23 (4), 583-607.

Bernat, F. P., Makin, D., 2014. Cybercrime theory and discerning if there is a crime: The case of digital piracy. International Review of Modern Sociology 40 (2), 99-119.

CBOS, 2013. Internauci 2013. Polish Public Opinion BS/75/2013, Centrum Badania Opinii Społecznej, Warszawa. 
Cheung, C. M., Lee, M. K., Rabjohn, N., 2008. The impact of electronic word-of-mouth: The adoption of online opinions in online customer communities. Internet Research 18 (3), 229-247.

Cole, J., 2013. Digital Future Report 11, Center for the Digital Future.

Denegri-Knott, J., 2004. Sinking the online "music pirates:" Foucault, power and deviance on the web. Journal of Computer-Mediated Communication 9 (4).

Easley, R. F., 2005. Ethical issues in the music industry response to innovation and piracy. Journal of Business Ethics 62 (2), 163-168.

Elster, J., 1989. Social norms and economic theory. The Journal of Economic Perspectives 3 (4), 99-117.

Ernesto, 2011. Piracy is not theft: Problems of a nonsense metaphor. Accessed 2014-03-04.

URL https://torrentfreak.com/piracy-is-not-theft-111104/

Glass, R. S., Wood, W. A., 1996. Situational determinants of software piracy: An equity theory perspective. Journal of Business Ethics 15 (11), 1189-1198.

Goles, T., Jayatilaka, B., George, B., Parsons, L., Chambers, V., Taylor, D., Brune, R., 2008. Softlifting: Exploring determinants of attitude. Journal of Business Ethics 77 (4), 481-499.

Gottschalk, P., Smith, R., 2011. Criminal entrepreneurship, white-collar criminality, and neutralization theory. Journal of Enterprising Communities: People and Places in the Global Economy 5 (4), 300308.

Green, S. P., 2012. Thirteen Ways to Steal a Bicycle: Theft Law in the Information Age. Harvard University Press.

Green, S. P., Kugler, M. B., 2010. Community perceptions of theft seriousness: A challenge to model penal code and english theft act consolidation. Journal of Empirical Legal Studies 7 (3), 511-537.

Gupta, P. B., Gould, S. J., Pola, B., Dec. 2004. "To Pirate or Not to Pirate": A Comparative Study of the Ethical Versus Other Influences on the Consumer's Software Acquisition-Mode Decision. Journal of Business Ethics 55 (3), 255-274.

Hart, R., 2012. Top 10 reasons people use to justify pirating digital content (and why they're wrong). Accessed 2014-03-04.

URL http://litreactor.com/columns/top-10-reasons-people-use-to-justify-piratin

Hasnas, J., 2004. Ethics and the problem of white collar crime. American University Law Review 54 (3), 579-655.

Higgins, G. E., Wilson, A. L., Fell, B. D., 2005. An application of deterrence theory to software piracy. Journal of Criminal Justice and Popular Culture 12 (3), 166-184.

Hill, C. W., 2007. Digital piracy: Causes, consequences, and strategic responses. Asia Pacific Journal of Management 24 (1), 9-25.

Hinduja, S., 2008. Deindividuation and internet software piracy. CyberPsychology \& Behavior 11 (4), 391-398. 
Holt, T. J., Copes, H., 2010. Transferring subcultural knowledge on-line: Practices and beliefs of persistent digital pirates. Deviant Behavior 31 (7), 625-654.

Homans, G. C., 1961. Social behavior: Its elementary forms. Harcourt, Brace.

Hunt, S. D., Vitell, S., 1986. A general theory of marketing ethics. Journal of Macromarketing 6 (1), $5-16$.

Introna, L. D., 2007. Singular justice and software piracy. Business Ethics: A European Review 16 (3), 264-277.

James, G., 2013. Why piracy is never okay. Accessed 2014-03-04.

URL http: / / amazingstoriesmag.com/2013/02/why-piracy-is-never-okay/

Krupka, E. L., Weber, R. A., 2013. Identifying social norms using coordination games: Why does dictator game sharing vary? Journal of the European Economic Association 11 (3), 495-524.

Ku, E. C., 2012. Beyond price: how does trust encourage online group's buying intention? Internet Research 22 (5).

Landes, W. M., Posner, R. A., 1989. An economic analysis of copyright law. Journal of Legal Studies 18,325 .

LaRose, R., Lai, Y. J., Lange, R., Love, B., Wu, Y., 2005. Sharing or piracy? an exploration of downloading behavior. Journal of Computer-Mediated Communication 11 (1), 1-21.

Lau, E. K.-w., 2007. Interaction effects in software piracy. Business Ethics: A European Review 16 (1), $34-47$.

Liang, J., Phau, I., 2012. Comparison of attitudes towards digital piracy between downloaders and nondownloaders. Korean Scholars of Marketing Science, Global Marketing Conference at Seoul.

Lin, H.-F., 2007. The role of online and offline features in sustaining virtual communities: an empirical study. Internet Research 17 (2).

Lin, T.-C., Hsu, M. H., Kuo, F.-Y., Sun, P.-C., 1999. An intention model-based study of software piracy. In: System Sciences, 1999. HICSS-32. Proceedings of the 32nd Annual Hawaii International Conference on. IEEE, pp. 8-pp.

Masnick, M., 2011. Minecraft creator says 'no such thing as a lost sale'. Accessed 2014-03-04. URL http://www.techdirt.com/articles/20110303/02203613336/minecraft-creator-sa

Moores, T., Chang, J., 2006. Ethical decision making in software piracy: Initial development and test of a four-component model. MIS Quarterly 30 (1), 167-180.

Mudrack, P. E., Mason, E. S., 2013. Dilemmas, conspiracies, and sophies choice: Vignette themes and ethical judgments. Journal of Business Ethics 118 (3), 639-653.

Ostrom, E., 2000. Collective action and the evolution of social norms. The Journal of Economic Perspectives 14 (3), 137-158. 
Phau, I., Teah, M., Lwin, M., 2013. Pirating Pirates of the Caribbean: The curse of cyberspace. Journal of Marketing Management 30 (3-4), 1-22.

Reavis Conner, K., Rumelt, R. P., 1991. Software piracy: An analysis of protection strategies. Management science 37 (2), 125-139.

Rettinger, D. A., Jordan, A. E., Peschiera, F., 2004. Evaluating the motivation of other students to cheat: A vignette experiment. Research in Higher Education 45 (8), 873-890.

Robertson, K., McNeill, L., Green, J., Roberts, C., 2012. Illegal downloading, ethical concern, and illegal behavior. Journal of Business Ethics 108 (2), 215-227.

Schoenberg, N. E., Ravdal, H., 2000. Using vignettes in awareness and attitudinal research. International Journal of Social Research Methodology 3 (1), 63-74.

Schultz, M., 2006. Copynorms: copyright and social norms. Social Science Research Network.

Schwartz, S. H., Tessler, R. C., 1972. A test of a model for reducing measured attitude-behavior discrepancies. Journal of Personality and Social Psychology 24 (2), 225.

Shang, R.-A., Chen, Y.-C., Chen, P.-C., 2008. Ethical decisions about sharing music files in the p2p environment. Journal of Business Ethics 80 (2), 349-365.

Siegfried, R. M., 2004. Student attitudes on software piracy and related issues of computer ethics. Ethics and Information Technology 6 (4), 215-222.

Steinert, T., Lepping, P., 2009. Legal provisions and practice in the management of violent patients. a case vignette study in 16 european countries. European Psychiatry 24 (2), 135-141.

Stolte, J. F., 1994. The context of satisficing in vignette research. The Journal of Social Psychology 134 (6), 727-733.

Sunstein, C. R., 1996. On the expressive function of law. University of Pennsylvania law review 144 (5), 2021-2053.

Svensson, M., Larsson, S., de Kaminski, M., 2014. The research bay - studying the global file sharing community. Law and Society Perspectives on Intellectual Property Law.

Sykes, G. M., Matza, D., 1957. Techniques of neutralization: A theory of delinquency. American sociological review 22 (6), 664-670.

Tang, J.-H., Farn, C.-K., 2005. The effect of interpersonal influence on softlifting intention and behaviour. Journal of Business Ethics 56 (2), 149-161.

Tassi, P., 2012. You will never kill piracy, and piracy will never kill you. Accessed 2014-05-17.

URL www. forbes.com/sites/insertcoin/2012/02/03/you-will-never-kill-piracy-and-r

Toral, S. L., Martinez-Torres, M. R., Barrero, F., Cortes, F., 2009. An empirical study of the driving forces behind online communities. Internet Research 19 (4). 
Wang, X., McClung, S. R., 2012. The immorality of illegal downloading: The role of anticipated guilt and general emotions. Computers in Human Behavior 28 (1), 153-159.

Williams, P., Nicholas, D., Rowlands, I., 2010. The attitudes and behaviours of illegal downloaders. In: Aslib Proceedings. Vol. 62. Emerald Group Publishing Limited, pp. 283-301.

Wilson, M., 2013. Piracy isn't theft, but its effects are wide and far-reaching. Accessed 2014-03-04.

URL http://betanews.com/2013/09/16/piracy-isnt-theft-but-its-effects-are-wide-

Wingrove, T., Korpas, A. L., Weisz, V., 2011. Why were millions of people not obeying the law? Motivational influences on non-compliance with the law in the case of music piracy. Psychology, Crime \& Law 17 (3), 261-276. 


\section{A Vignettes (stories): Study 1}

1. Johnny borrowed some notes from his classmate. The materials were kept on a USB flash drive. Besides them, it contained a season of a popular TV series original, and in high quality. Without asking for permission or informing the owner, Johnny copied the series and returned the flash drive

2. While visiting a friend in his house, Johnny noticed that among a huge DVD collection of TV series, many either had duplicates or were unopened including a DVD of one popular TV series. The owner doesn't have time or the will to watch them. Given the opportunity of being alone in the room, Johnny put one of the unpacked duplicates in his backpack, in order to take it back home and claim it as his own.

3. Johnny intended to borrow and copy (for personal use) his friend's DVD of a popular TV series, knowing that his friend was OK with it. However, his friend left town before Johnny had the opportunity to ask him and so, given the opportunity while taking care of his friend's dog, he decided to take the DVD without asking for permission. Johnny doesn't intend on giving the series back after watching it.

4. A friend of Johnny's forgot to log out from his e-mail box after using Johnny's computer. While closing the web browser, Johnny spotted that the mail currently displayed on his screen contained a one-use-only access code to a payable site with TV series in High Definition. Johnny quickly copied the code, and after returning home used it on a season of a popular TV series.

5. Johnny searched the Internet for episodes of a popular TV series. Not being able to find them he bought a season of the series on DVD. However, he decided that it's unthinkable for the series not to be available online. After receiving his package he saved the episodes in AVI format and shared them publicly on the Internet.

6. Johnny searched the Internet for episodes of a popular TV series. Not being able to find them he bought a season of the series on DVD. However, he decided that it's unthinkable for the series not to be available online. After receiving his package he cracked the DRM protection, saved the episodes in AVI format and shared them publicly on the Internet.

7. Johnny searched the Internet for episodes of a popular TV series. Not being able to find them he borrowed a season of the series on DVD from his friend. However, he decided that it's unthinkable for the series not to be available online. After receiving his package he saved the episodes in AVI format and shared them publicly on the Internet.

8. Johnny searched the Internet for episodes of a popular TV series. Not being able to find them he borrowed a season of the series on DVD from his friend. However, he decided that it's unthinkable for the series not to be available online. After receiving his package he cracked the DRM protection, saved the episodes in AVI format and shared them publicly on the Internet.

9. Johnny found and downloaded from a site allowing sharing and downloading files without their authors' knowledge, a full season of TV series created by his friend - a debuting, independent director whom he once met at a film workshop. 
10. Johnny found and downloaded from a site allowing sharing and downloading files without their authors' knowledge, the newest season of a high budget, American TV series.

11. Johnny downloaded a full season of a high budget, American TV series through a P2P network, while sharing it with other users simultaneously.

12. Johnny downloaded a full season of a high budget, American TV series through a P2P network. Johnny didn't allow for other users to download the files from him (blocked sharing channel).

13. A new season of a popular, high budget, American TV series is available in kiosks as an add-on to a magazine priced 7,99 Zloty. However, Johnny downloaded the series from another source, for free.

14. Johnny went shopping to a hypermarket in which DVDs with films and series are also available. While walking among the shelves he saw that one of the DVDs with a season of a popular, high budget, American series doesn't have the anti-theft sticker on it. Johnny waited for the shop's staff to look the other way and took his favorite series.

15. During a break between classes, Johnny's friends went to a bar to buy something to eat. From previous talk, Johnny knew that in one of his friend's backpack there was a DVD with a season of a popular, high budget American TV series. Johnny opened the backpack and put the DVD into his own bag without being noticed. Johnny didn't intend on giving the DVD back after watching it.

16. Johnny's friend - a debutant director whom he met during film workshops - shares the first season of his series on his own website, on a pay-what-you-want basis, without setting a minimum price requirement. Johnny heard about this from common friends, but he downloaded episodes of the season from a popular website, which allows its users to upload and download files.

17. Johnny's friend - a debutant director whom he met during film workshops - shares the first season of his series on his own website, on a pay-what-you-want basis, without setting a minimum price requirement. Johnny heard about this from common friends, and, taking interest in the plot, downloaded all the episodes through a P2P network, while sharing it with other users simultaneously.

18. Johnny's friend - a debutant director whom he met during film workshops - shares the first season of his series on his own website, on a pay-what-you-want basis, without setting a minimum price requirement. Johnny heard about this from common friends, and, taking interest in the plot, downloaded all the episodes through a P2P network. Johnny doesn't allow for other users to download the files from him (blocked sharing channel). 


\section{B Vignettes (stories): Study 2}

[penalty] was manipulated between subject. It was:

- "Johnny is not going to face any sanctions because of what he did" in the NoPenalty condition

- "The manager will not allow Johnny to DJ at the club any more if he finds out what Johnny did" in the Penalty condition

[price] was manipulated within subject. It was:

- 400 pln in the Low Price condition and

- 2000 pln in the High Price condition

\section{Screen A: online stories}

NoLoss condition: Johnny is an amateur DJ in a club. One night he noticed another DJ logging in to a premium account at a music streaming platform. Johnny wrote down the password so that from now on he could also use the account when DJ-ing. [pen]. Johnny would have to make a one-time payment of [price] to get his own premium account at the platform.

Loss condition: Johnny is an amateur DJ in a club. One night he noticed another DJ logging in to a premium account at a music streaming platform. Johnny wrote down the password, logged on and changed the password, so that from now on only he could use the account when DJ-ing. [pen]. Johnny would have to make a one-time payment of [price] to get his own premium account at the platform.

\section{Screen B: offline, non-physical stories}

NoLoss condition: Johnny is an amateur DJ in a club. One night he noticed another DJ accidentally left his laptop with a music collection. Johnny copied the files to his own device, so that from now on he could also use the account when DJ-ing. [pen]. Johnny would have to make a one-time payment of [price] to get his own premium account at the platform.

Loss condition: Johnny is an amateur DJ in a club. One night he noticed another DJ accidentally left his laptop with a music collection . Johnny cut and pasted the files to his own device, so that from now on only he could use the account when DJ-ing. [pen]. Johnny would have to make a one-time payment of [price] to get his own premium account at the platform.

\section{Screen C: offline, physical stories}

NoLoss condition: Johnny is an amateur DJ in a club. One night he noticed another DJ accidently left a flash-drive memory with a music collection. Johnny copied the files to his own computer, so that from now on he could also use the account when DJ-ing. [pen]. Johnny would have to make a one-time payment of [price] to get his own premium account at the platform. 
Loss condition: Johnny is an amateur DJ in a club. One night he noticed another DJ accidently left a flash-drive memory with a music collection. Johnny replaced the flash drive with an analogous, but empty one, so that from now on only he could use the account when DJ-ing. [pen]. Johnny would have to make a one-time payment of [price] to get his own premium account at the platform. 